\title{
Hepatocellular Uptake of Taurocholate in the Dog
}

\author{
Juan-Carlos Glasinović, Micheline Dumont, Michel Duval, and \\ Serge ErLinger \\ From the Unité de Recherches de Physiopathologie Hépatique (INSERM), \\ Hôpital Beaujon, 92110 Clichy, France
}

\begin{abstract}
A в STRACT The purpose of this study was to examine the hepatocellular extraction of taurocholate and to determine the kinetic characteristics of the uptake process. The uptake of taurocholate by the liver of the intact dog was studied by the multiple-indicator dilution method. ${ }^{51} \mathrm{Cr}$-labeled red blood cells (a vascular indicator), ${ }^{125} \mathrm{I}$-labeled albumin (an extravascular reference), and $\left[{ }^{14} \mathrm{C}\right]$ taurocholate were injected into the portal vein. Different doses of unlabeled taurocholate were included in the injection mixture. Hepatic venous dilution curves were obtained. As a consequence of the hepatic uptake, the outflow recovery of $\left[{ }^{11} \mathrm{C}\right]$ taurocholate was much reduced when compared to that of albumin, but its recovery increased with increasing doses of taurocholate, suggesting a progressive saturation of the uptake process. The analysis of the dilution curves fitted a three-compartment model system well and no return of the extracted taurocholate to the extracellular space could be detected. The initial space of distribution of taurocholate was $1.22 \pm 0.12$ (SD) times greater than that of albumin. Analysis of the data for uptake was consistent with Michaelis-Menten kinetics. The calculated initial maximal velocity of uptake ( $V \max$ ) was $4.53 \mu \mathrm{mol} \cdot \mathrm{s}^{-1} \cdot 100 \mathrm{~g}$ of liver ${ }^{-1}$ and the dose yielding half-maximal velocity $\left(K_{D}\right)$ was $7.11 \mu \mathrm{mol} \cdot 100 \mathrm{~g}$ of liver $^{-1}$. These results are consistent with the hypothesis that the uptake of taurocholate is carrier-mediated. The maximal velocity of uptake was about six times the known maximal capacity of biliary secretion of taurocholate in the dog.
\end{abstract}

\section{INTRODUCTION}

Although it is generally assumed that the hepatic handling of bile acids consists of three steps (hepatic up-

This work was presented in part at the 8th meeting of the European Association for the Study of the Liver, Vittel, France, 7-8 September 1973 and abstracted in Digestion. 8: 432-433. 1973.

Received for publication 8 April 1974 and in revised form 16 October 1974. take, intracellular transport, and biliary excretion), the mechanism by which these organic anions are taken up by the liver is completely unknown. O’Máille, Richards, and Short have shown that in the dog the extraction of labeled taurocholate from plasma is about $90 \%$ during a single passage through the liver (1). This efficiency of extraction is remarkable and greater than the hepatic extraction of sulfobromophthalein $(B S P)^{1}(2)$ and most other compounds.

Goresky has studied the uptake of BSP by the liver of the dog and shown that this process was saturable, a finding consistent with the presence of a carrier-mediated transport system (3). The multiple-indicator dilution technique permitted an estimation of the maximal initial velocity of the transport process, and of the extravascular concentration yielding half-maximal initial velocity.

The high extraction efficiency of the liver for bile acids suggests an active or carrier-mediated transport system for these compounds. The purpose of this study was to examine the hepatocellular extraction of taurocholate and to determine the kinetic characteristics of the uptake process. A multiple-indicator dilution technique essentially similar to that used for BSP by Goresky was employed, assuming a flow-limited three-compartment model. The results are consistent with MichaelisMenten kinetics, and hence, with the existence of a carrier-mediated transport system.

\section{METHODS}

\section{Experimental procedures}

22 experiments were performed in $8 \mathrm{dogs}(18-24 \mathrm{~kg})$. The dogs were anesthetized with $1 \mathrm{mg} / \mathrm{kg}$ of $5 \%$ sodium pentobarbital ${ }^{2}$ and maintained under artificial respiration. A $0.15 \mathrm{M} \mathrm{NaCl}$ solution was infused into the femoral vein throughout the experiment at a rate of $0.2-0.5 \mathrm{ml} / \mathrm{min}$.

\footnotetext{
${ }^{1}$ Abbreviations used in this paper: BSP, sulfobromophthalein; $K_{D}$, plasma concentration yielding half-maximal velocity; $V$ max, initial maximal velocity of uptake.

${ }^{2}$ Nembutal, Abbott Laboratories, St. Rémy-sur-Avre, France.
} 
Arterial pressure was continuously recorded from the femoral artery with an electric manometer.

Under fluoroscopic examination, a radio-opaque catheter was placed into the left hepatic vein through the jugular vein. The catheter was continuously perfused and flushed with a $0.15 \mathrm{M} \mathrm{NaCl}$ solution to prevent clotting. A lower midabdominal incision was made and a radio-opaque catheter was introduced through an intestinal vein into the portal vein, and fixed approximately $5 \mathrm{~cm}$ under its bifurcation. The abdomen was closed and $50 \mathrm{mg}$ of heparin was injected into the jugular catheter.

The rapid single-injection multiple-indicator dilution technique was used. In each experiment a tracer dose of [24 $\left.{ }^{14} \mathrm{C}\right]$ sodium taurocholate was injected simultaneously with two reference tracers: ${ }^{51} \mathrm{Cr}$-labeled red cells as a vascular indicator and ${ }^{100} \mathrm{I}$-labeled albumin ${ }^{5}$ as an extravascular indicator. In each injection a known dose of unlabeled taurocholate was included. Thus, the total dose of taurocholate in the injection mixture was varied at each injection. The implications of this procedure for the analysis of the results will be discussed under "Description of the model". Taurocholate was dissolved in dog plasma and mixed with the labeled albumin and the $\left[{ }^{14} \mathrm{C}\right]$ taurocholate. The total volume of the mixture was about $1 \mathrm{ml}$. ${ }^{5} \mathrm{Cr}$-labeled red cells were separately resuspended in the dog plasma, with a final volume of about $0.5 \mathrm{ml}$ and with a hematocrit adjusted to match that of the peripheral blood of the dog. To prevent hemolysis of labeled red cells by taurocholate, the labeled red cells and the mixture containing the labeled taurocholate and albumin were separately introduced in the injection catheter. The material was then flushed into the portal vein in a rapid injection with $5 \mathrm{ml}$ of $0.15 \mathrm{M} \mathrm{NaCl}$, to produce turbulence and hence, presumably, a complete mixing at the point of the injection. Hepatic venous samples were taken every $2 \mathrm{~s}$ from the outflow catheter through a sigmoid pump. The collection catheter had a volume of $2.4 \mathrm{ml}$ and the sampling rate ranged between 1.0 and $1.5 \mathrm{ml} / \mathrm{s}$. With the doses of taurocholate used, no hemolysis was observed in the peripheral blood. Whole blood or dextran was injected during the sampling period at the same rate as the sampling. Two to four sets of dilution curves were obtained in the same animal, with an interval of at least $45 \mathrm{~min}$. It was verified in two dogs that the removal rate constant $(k)$ and extraction calculated (as indicated below) from two sets of dilution curves with the same dose of taurocholate, obtained $90 \mathrm{~min}$ apart, differed by less than $10 \%$.

\section{Analytical procedures}

The activities of ${ }^{51} \mathrm{Cr}$ and ${ }^{125} \mathrm{I}$ were measured in $500 \mu \mathrm{l}$ of blood in a Nuclear Chicago scintillation spectrometer. ${ }^{14} \mathrm{C}$ activity was measured in a liquid scintillation spectrometer $^{7} ; 50 \mu \mathrm{l}$ of plasma were deposited on glass-fiber disks (Whatman GF/C, $1.9 \mathrm{~cm}$ ) and $1 \mathrm{ml}$ of NE 220 scintillation medium ${ }^{8}$ was added. Correction for contamination by gamma-emitting isotopes was made with appropriate standards. A fraction of the injection mixture was diluted in plasma and processed and analyzed in the same way. Hematocrit was measured to adjust taurocholate (counted

Telco, St. Cloud, France.

The Radiochemical Centre, Amersham, Bucks, England.

- Commissariat à l'Energie Atomique, Gif-sur-Yvette, France.

- Nuclear-Chicago Corp., Des Plaines, Ill.

'Intertechnique ABAC SL 40, Plaisir, France.

${ }^{8}$ Nuclear Enterprises Ltd., Edinburgh, Scotland. on plasma) with albumin and red blood cell (counted on whole blood) activities. $\left.{ }^{14} \mathrm{C}\right]$ Taurocholate activity was counted on plasma rather than on whole blood, because it has been established by in vitro studies that taurocholate is virtually confined to plasma (1).

\section{Calculations}

Recoveries. The concentration of each indicator in the hepatic venous outflow was expressed as a fraction of the injected amount per milliliter of blood. The outflow recoveries of labeled red cells and $\left.{ }^{11} \mathrm{C}\right]$ taurocholate were calculated as the fraction of the recovered ${ }^{125}$ I-labeled albumin. For taurocholate, the extraction corresponds to $1-$ its recovery.

Blood flow and transit times. The outflow dilution curves were corrected for recirculation by linear extrapolation of the downslope on a semilogarithmic plot (4). Hepatic blood flow was estimated by the Stewart-Hamilton principle from the dilution curves (5). The mean transit times were measured by the procedure described by Meier and Zierler (5) and corrected by subtraction for the catheter transit times (6). Zero time $\left(t_{0}\right)$, which corresponds to the time spent by the labels in the large vessels, where no exchange or removal took place, was calculated according to the formula (7) $t_{0}=\left[t_{\mathrm{RBC}}(1+\gamma)-t_{\mathrm{A1b}}\right] / \gamma$ where $t_{\mathrm{RBC}}$ is the transit time at the peak 'of the labeled red cell dilution curve; $t_{\mathrm{Alb}}$, the transit time at the peak of the labeled albumin dilution curve; $\gamma$, the ratio of the extravascular distribution volume to the vascular distribution volume; and $(1+\gamma)$ is computed as the ratio of the peak red cell concentration to the peak albumin concentration.

Kinetic analysis. The determinations of the removal rate constant, the hepatic taurocholate concentration, the initial removal rate, and the kinetic analysis were performed as indicated under results.

\section{RESULTS}

Mean transit times and plasma flows are shown in $\mathrm{Ta}$ ble I. The outflow recovery of labeled red cells corresponds to $1.03 \pm 0.05$ ( $\mathrm{SEM}$ ) times that of labeled albumin.

Fig. 1 illustrates the outflow profile for an experiment carried out with a dose of taurocholate of $3.3 \mu \mathrm{mol} / 100$ $g$ of liver. The upper panel is rectilinear and the lower semilogarithmic. The red cell curve has the highest and earliest peak and then decays rapidly. The albumin curve has a lower and later peak and decays less quickly than that of red cells. The areas under both curves are equal when recirculation is excluded by extrapolation of the downslopes. The $\left[{ }^{14} \mathrm{C}\right]$ taurocholate emerges at the outflow at the same time as the I-labeled albumin, but when the taurocholate dilution curve was compared to that of albumin, two differences were noted: $(a)$ the area of the taurocholate dilution curve was smaller than that of the albumin dilution curve; and $(b)$ after the peak, the concentration of taurocholate decayed more rapidly than that of albumin, so that a progressive divergence between the two curves with time was apparent.

Fig. 2 illustrates the set of dilution curves obtained in an experiment carried out with a dose of taurocholate of $16.3 \mu \mathrm{mol} / 100 \mathrm{~g}$ of liver. It can be seen that the 
TABLE I

Transit Time and Flow Data from the Dilution Curves

\begin{tabular}{|c|c|c|c|c|c|c|c|c|}
\hline $\begin{array}{c}\text { Dog } \\
\text { no. }\end{array}$ & $\begin{array}{c}\text { Expt. } \\
\text { nc. }\end{array}$ & $\begin{array}{c}\text { Body } \\
\text { wt }\end{array}$ & $\begin{array}{c}\text { Liver } \\
\text { wt }\end{array}$ & $\begin{array}{c}\text { Hepatic } \\
\text { blood } \\
\text { flow }\end{array}$ & $\begin{array}{c}\bar{t} \\
\mathrm{RBC}^{2}\end{array}$ & $\begin{array}{c}\bar{t} \\
\text { Alb } \ddagger\end{array}$ & $\begin{array}{c}\bar{t} \\
\text { ref } \$\end{array}$ & $\begin{array}{c}\bar{t} \\
\mathrm{TC} \|\end{array}$ \\
\hline & & & & $m l \cdot s^{-1}$ & & & & \\
\hline & & kg & $g$ & $100 \mathrm{~g}^{-1}$ & $s$ & $s$ & $s$ & $s$ \\
\hline \multirow[t]{2}{*}{1} & 1 & 24 & 720 & 2.54 & 5.1 & 10.1 & 11.1 & 9.7 \\
\hline & 2 & & & 2.86 & 4.2 & 8.7 & 9.4 & 8.5 \\
\hline \multirow[t]{3}{*}{2} & 3 & 14 & 420 & 6.54 & 9.6 & 14.2 & 14.2 & 10.8 \\
\hline & 4 & & & 4.73 & 10.3 & 15.7 & 15.7 & 12.1 \\
\hline & 5 & & & 4.97 & 6.1 & 11.9 & 13.4 & 10.1 \\
\hline \multirow[t]{3}{*}{3} & 6 & 19 & 570 & 1.82 & 10.3 & 17.7 & 21.2 & 2.6 \\
\hline & 7 & & & 1.88 & 9.6 & 17.6 & 20.5 & 17.7 \\
\hline & 8 & & & 2.16 & 8.7 & 17.2 & 19.7 & 11.5 \\
\hline \multirow[t]{4}{*}{4} & 9 & 23 & 560 & 1.82 & 11.2 & 22.4 & 25.4 & 22.0 \\
\hline & 10 & & & 2.30 & 14.2 & 23.4 & 27.8 & 19.0 \\
\hline & 11 & & & 2.03 & 14.1 & 23.6 & 27.6 & 19.0 \\
\hline & 12 & & & 0.88 & 15.4 & 32.7 & 37.3 & 23.3 \\
\hline \multirow[t]{4}{*}{5} & 13 & 18 & 540 & 1.82 & 9.1 & 19.1 & 20.8 & 15.0 \\
\hline & 14 & & & 1.52 & 21.7 & 36.0 & 46.0 & 21.7 \\
\hline & 15 & & & 2.42 & 10.4 & 20.6 & 22.7 & 15.5 \\
\hline & 16 & & & 3.45 & 8.4 & 17.5 & 17.5 & 15.2 \\
\hline \multirow[t]{2}{*}{6} & 17 & 18 & 650 & 2.24 & 11.1 & 23.1 & 23.1 & 17.0 \\
\hline & 18 & & & 2.00 & 11.3 & 23.5 & 23.5 & 18.3 \\
\hline 7 & 19 & 20 & 540 & 1.33 & 15.0 & 25.9 & 31.0 & 19.4 \\
\hline \multirow[t]{3}{*}{8} & 20 & 18 & 560 & 2.00 & 7.5 & 14.3 & 16.4 & 12.8 \\
\hline & 21 & & & 2.44 & 6.6 & 12.5 & 14.4 & 13.6 \\
\hline & 22 & & & 1.91 & 8.2 & 14.9 & 17.4 & 12.2 \\
\hline
\end{tabular}

$* \bar{t} \mathrm{RBC}$, mean transit time of red blood cells.

$\ddagger \bar{t}$ Alb, mean transit time of albumin.

$\S \bar{t}$ ref, mean transit time of the adequate reference substance for taurocholate. These mean transit times were obtained from the theoretical dilution curves that correspond to the space of distribution of taurocholate and that have been obtained by modification of the dilution curves of albumin.

$\| \bar{t} \mathrm{TC}$, mean transit time of taurocholate.

difference of area between ${ }^{125} \mathrm{I}$-labeled albumin and $\left[{ }^{14} \mathrm{C}\right]$ taurocholate has decreased as the dose of taurocholate increased.

As can be seen in Table II, the fraction of the dose of taurocholate extracted in one passage through the liver roughly decreased as the dose of taurocholate increased. This suggests a progressive saturation of the uptake process.

To interpret the results in adequate terms for a kinetic analysis, the model originally proposed by Goresky for BSP (3) and modified as proposed by Goresky, Bach, and Nadeau (8) was used. Its main characteristics will be indicated below.

\section{Description of the model}

This is a three-compartment model system that includes a vascular compartment (A), an extravascular compartment (B), and a cellular compartment (C). The basic assumptions underlying the model are: $(a)$ flow is confined to the vascular compartment; $(b)$ there is no diffusion along the length in $\mathrm{A}$ and $\mathrm{B} ;(c)$ there is a bolus flow, that is, red cells and plasma move with the same velocity; $(d)$ there is an instantaneous diffusion of diffusible labels from $A$ to $B$; $(e)$ if the total extracellular space (vascular + extravascular) is divided into multiple successive theoretical elements, removal of taurocholate from extracellular to cellular space is irreversible and takes place at a rate proportional to the taurocholate plasma concentration. In this model, the outflow concentration profile consists of two terms, a throughput component and a returning component. The concentration of the extracted substance, $Q(t)$ e, is related to the concentration of its appropriate reference, $Q(t)_{\text {ref, by the equation: }}$

$$
Q(t)_{e}=e^{-k_{1} \theta t / 1+\gamma} Q(t)_{r e f}+\text { returning material }
$$

where $k_{1}$ is the removal rate constant describing the transport of the extracted substance into the cellular compartment, $\theta$ the ratio of the cellular space (C) to the sinusoidal vascular space $(A)$, and $\theta /(1+\gamma)$ the

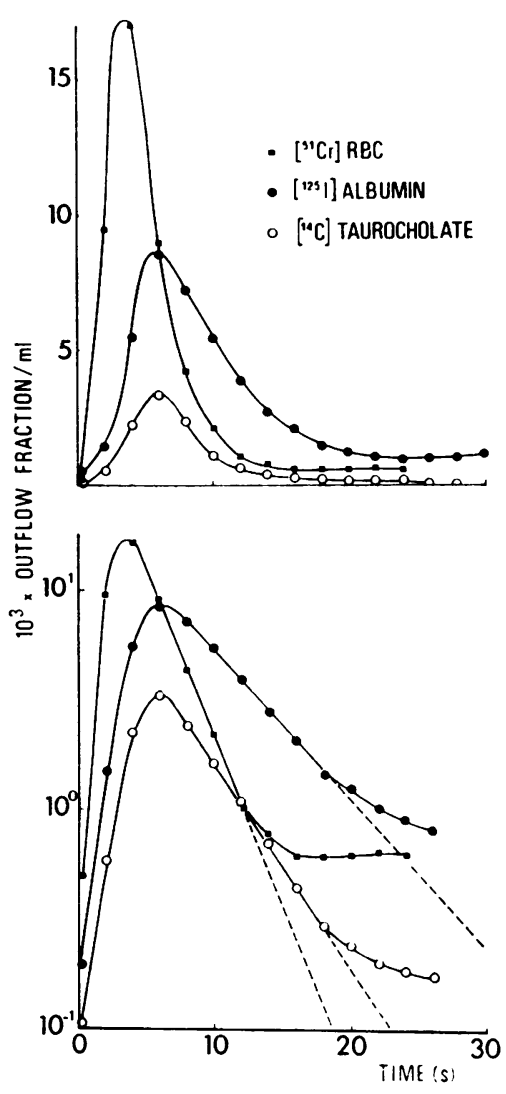

Figure 1 Outflow profile for an experiment carried out with a dose of taurocholate of $3.3 \mu \mathrm{mol} / 100 \mathrm{~g}$ of liver. Abcissas: time in seconds. Ordinates: outflow recovery per milliliter (expressed as fraction of the injected dose), plotted in a rectilinear scale (upper panel) and in a logarithmic scale (lower panel). The experiment illustrated is numbered 20 in the tables. 


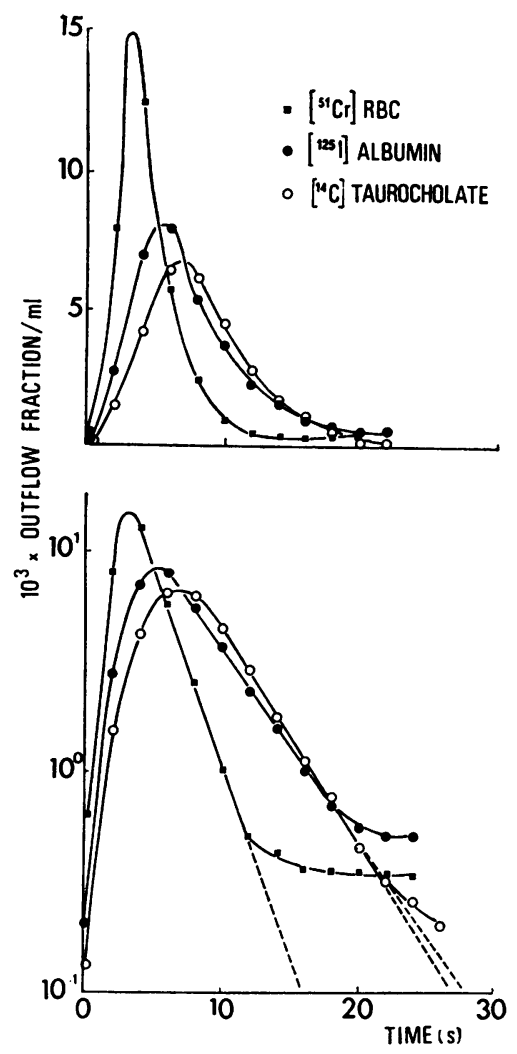

Figure 2 Outflow profile for an experiment carried out with a dose of taurocholate of $16.3 \mu \mathrm{mol} / 100 \mathrm{~g}$ of liver. Symbols are the same as in Fig. 1. Note that the taurocholate curve is not contained within the area of the albumin curve: this is because albumin is not the correct reference in this case. The appropriate reference curve has been calculated as indicated in the text. The experiment illustrated is numbered 21 in the tables.

ratio of the cellular space to the total space, vascular + extravascular, outside the cells.

In our study, where a single injection rather than a constant infusion was used, the cellular compartment may be viewed as virtually empty at the beginning of the experiment; the returning material may then be neglected and Eq. 1 transformed into :

$$
\ln \frac{Q(t)_{r e f}}{Q(t)_{e}}=\frac{k_{1} \theta t}{1+\gamma}
$$

$k_{1} \theta / 1+\gamma$ may be estimated as the slope of a plot of the natural logarithm of the ratio of the reference substance to taurocholate outflow fraction vs. time (8); if we know $1+\gamma, k_{1} \theta$ may be calculated; it has these dimensions: equivalent milliliters of plasma transported per second per milliliter sinusoidal plasma (or $\mathrm{s}^{-1}$ ).

\section{Analysis of the results}

Application of the model. Three values are needed for the kinetic analysis: (a) the concentration of tauro- cholate initially available for extraction; $(b)$ the removal rate constant; and (c) the initial removal rate of taurocholate from plasma into the hepatic cell. These data can be obtained from the application of the model. First, the appropriate reference dilution curve is needed, that is, one which would have been given by a substance with the same space of distribution as that of taurocholate and which would be completely recovered in the outflow. The graphic method of Goresky (3) was utilized to select the appropriate reference dilution curve and in consequence its space of distribution, and to determine the factor $k_{1} \theta /(1+\gamma)$. The application of this graphic procedure is shown in Fig. 3. In Fig. 3A the dilution curves of ${ }^{125} \mathrm{I}$-labeled albumin and $\left[{ }^{14} \mathrm{C}\right]$ taurocholate obtained in one experiment are represented in a semilogarithmic plot. Zero time $\left(t_{0}\right)$ has been calculated to exclude the times of transit through the nonexchanging larger vessels. In Fig. 3B a plot of the natural logarithm of the ratio of ${ }^{198} \mathrm{I}$-labeled albumin concentration to $\left[{ }^{14} \mathrm{C}\right]$ taurocholate concentration is represented. A straight line was not obtained. This graphic result suggests that $\left[{ }^{14} \mathrm{C}\right]-$ taurocholate has undergone an initial distribution in the liver beyond the space of distribution of albumin; therefore, the albumin dilution curve was not the appropriate reference curve in this case. The larger distribution space for taurocholate may be explained by the observation that the extravascular space available to sucrose,

TABLE II

Dose of Taurocholate and Derived Parameters

\begin{tabular}{|c|c|c|c|c|c|c|}
\hline $\begin{array}{c}\text { Exp. } \\
\text { no. }\end{array}$ & $\begin{array}{l}\text { Dose } \\
\text { of TC }\end{array}$ & $\begin{array}{c}\text { TC } \\
\text { extrac- } \\
\text { tion }\end{array}$ & $k_{1} \theta /(1+\gamma)$ & $k_{1} \theta$ & $\begin{array}{c}\text { Initial } \\
\text { removal } \\
\text { rate* }\end{array}$ & $\frac{\text { TC space }}{\text { Alb space }}$ \\
\hline & $\begin{array}{c}\mu m o l \cdot 100 \mathrm{~g} \\
\text { liver }^{-1}\end{array}$ & $\%$ & $s^{-1}$ & $s^{-1}$ & $\begin{array}{c}\mu \mathrm{mol} \cdot 100 \mathrm{~g} \\
\text { liver }^{-1} \cdot \mathrm{s}^{-1}\end{array}$ & \\
\hline 1 & 1.67 & 66 & 0.111 & 0.270 & 0.450 & 1.25 \\
\hline 2 & 10.00 & 33 & 0.097 & 0.242 & 2.240 & 1.25 \\
\hline 3 & 0.23 & 76 & 0.290 & 0.584 & 0.134 & 1.00 \\
\hline 4 & 2.33 & 88 & 0.120 & 0.241 & 0.561 & 1.25 \\
\hline 5 & 2.80 & 72 & 0.297 & 0.778 & 2.178 & 1.30 \\
\hline 6 & 2.96 & 80 & 0.230 & 0.602 & 1.781 & 1.30 \\
\hline 7 & 5.53 & 67 & 0.175 & 0.458 & 2.532 & 1.25 \\
\hline 8 & 1.32 & 84 & 0.230 & 0.634 & 0.836 & 1.25 \\
\hline 9 & 3.59 & 78 & 0.198 & 0.542 & 1.945 & 1.25 \\
\hline 10 & 7.20 & 63 & 0.120 & 0.288 & 2.073 & 1.25 \\
\hline 11 & 10.84 & 60 & 0.075 & 0.175 & 1.897 & 1.25 \\
\hline 12 & 14.40 & 60 & 0.059 & 0.175 & 2.520 & 1.25 \\
\hline 13 & 1.27 & 77 & 0.200 & 0.538 & 0.638 & 1.50 \\
\hline 14 & 2.79 & 92 & 0.220 & 0.682 & 1.902 & 1.25 \\
\hline 15 & 6.57 & 74 & 0.140 & 0.347 & 2.279 & 1.00 \\
\hline 16 & 16.44 & 62 & 0.087 & 0.168 & 2.791 & 1.00 \\
\hline 17 & 8.30 & 78 & 0.115 & 0.241 & 2.000 & 1.00 \\
\hline 18 & 9.70 & 75 & 0.111 & 0.231 & 2.240 & 1.25 \\
\hline 19 & 2.38 & 82 & 0.123 & 0.319 & 0.759 & 1.25 \\
\hline 20 & 3.26 & 67 & 0.146 & 0.379 & 1.235 & 1.25 \\
\hline 21 & 16.33 & 9 & 0.058 & 0.150 & 2.449 & 1.25 \\
\hline 22 & 3.26 & 80 & 0.152 & 0.395 & 1.287 & 1.25 \\
\hline
\end{tabular}

Alb, albumin; TC, taurocholate.

* Calculated as the product of the removal rate constant, $k_{1} \theta$, and the dose per 100 grams of liver. 

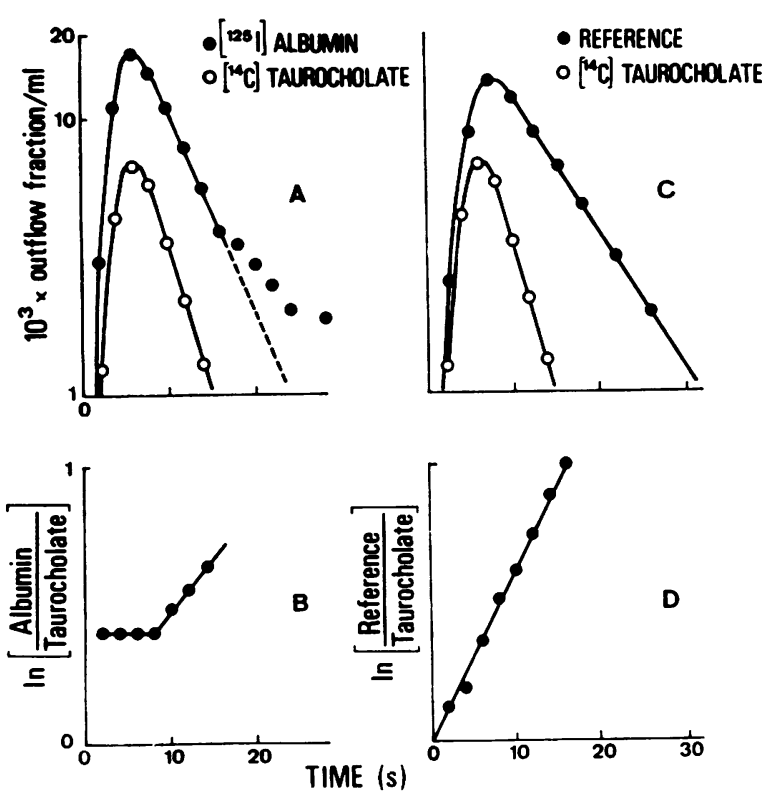

FIgURE 3 Graphical determination of the appropriate reference dilution curve and of the rate constant $k_{1} \theta$. The experimental dilution curves are shown in $\mathrm{A}$; the plot of the natural logarithm of the ratio ${ }^{125}$ I-labeled albumin/ $\left[{ }^{14} \mathrm{C}\right]$ taurocholate vs. time is shown in $\mathrm{B}$; the corresponding curves and plots for the theoretical appropriate reference are shown in $\mathrm{C}$ and $\mathrm{D}$. The slope of the straight line obtained in $\mathrm{D}$ corresponds to $k_{1} \theta /(1+\gamma)$.

a substance excluded from liver cells in one passage, is larger than that available to albumin (7); as will be discussed later, the access of taurocholate to a larger distribution space than that of albumin suggests that this bile salt is not tightly bound to albumin. The theoretical dilution curves for progressively greater spaces of distribution have been obtained from the transformation of the albumin dilution curve, in agreement with the properties of the dilution curves of a flow-limited distributed substance (7). From this set of theoretical dilution curves, the one whose concentrations maintained a single exponential ratio through time with the corresponding concentration of $\left[{ }^{14} \mathrm{C}\right]$ taurocholate was chosen. This new curve is represented in Fig. 3C, with the corresponding experimental dilution curve of $\left[{ }^{13} \mathrm{C}\right]$ taurocholate; a straight line resulted from the plot of the natural logarithm of the ratio of the concentrations of the new curve to those of $\left[{ }^{14} \mathrm{C}\right]$ taurocholate vs. time with origin at $t_{0}$ (Fig. 3D).

By this procedure the initial space of distribution and the removal rate constant, $k_{1} \theta$, for taurocholate were obtained in each experiment. The removal rate constant, $k_{x} \theta$, represents essentially the quotient of the PS product at the cellular surface to the plasma volume in the related sinusoid, $\mathrm{P}$ being the permeability in centimeters per second and $S$ the surface area of the capillary in centimeters squared.

As the real concentration of taurocholate in the portal vein cannot be obtained, the additional assumption (whose validity will be discussed later) was made that the extravascular taurocholate was initially distributed along the whole length of the sinusoid (3). The removal rate constant, $k_{1} \theta$, times the dose of taurocholate gave the initial removal rate of taurocholate, $v$.

Results of analysis. The values obtained in each experiment for the removal rate constant, $k_{1} \theta$, the factor $k_{1} \theta /(1+\gamma)$, and the initial removal rate of taurocholate are shown in Table II. The calculated initial space of distribution for taurocholate was on the average greater than that of albumin. The mean ratio of taurocholate to albumin spaces was $1.22 \pm 0.12$ (SD). No increase in the apparent space of distribution of taurocholate was observed with increasing doses in the range of doses studied (Fig. 4).

The influence of the dose on the removal rate constant, $k_{1} \theta$, is shown in Fig. $5 ; k_{1} \theta$ decreased as the dose increased. Similarly, the influence of the dose on the factor $k_{1} \theta /(1+\gamma)$ is shown in Fig. 6; this factor decreased as the dose increased.

The initial velocity of uptake increased nonlinearly with increasing doses of taurocholate, as shown in Fig. 7. Michaelis-Menten kinetics were then assumed; the parameters of the Michaelis-Menten equation

$$
v=V \max D /\left(K_{D}+D\right)
$$

where $v$ is the initial velocity of uptake, $D$ the dose of taurocholate per $100 \mathrm{~g}$ of liver, $V$ max the maximal initial velocity of uptake, and $K_{D}$ the dose yielding halfmaximal velocity, were calculated in three ways: $(a)$ by using a digital computer program to identify mathematically $V \max$ and $K_{D} ;(b)$ after linear transformation of the data according to Woolf, when Eq. 3 has been

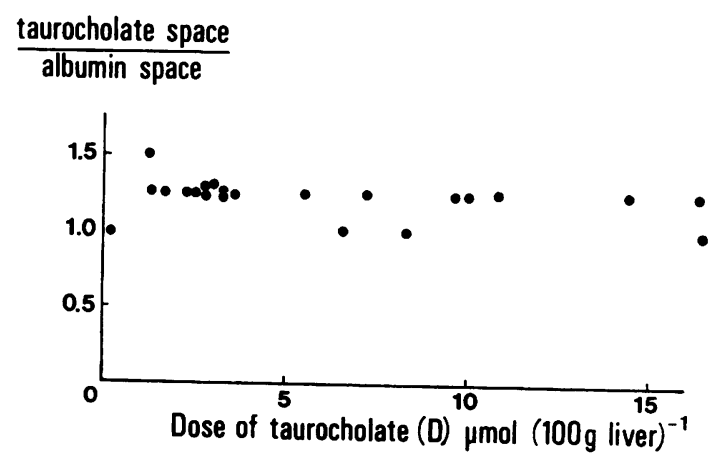

FIGURE 4 Initial space of distribution of taurocholate. The space of distribution of taurocholate was, on the average, $1.22 \pm 0.12$ (SD) times greater than that of albumin and did not increase with increasing doses of taurocholate. 


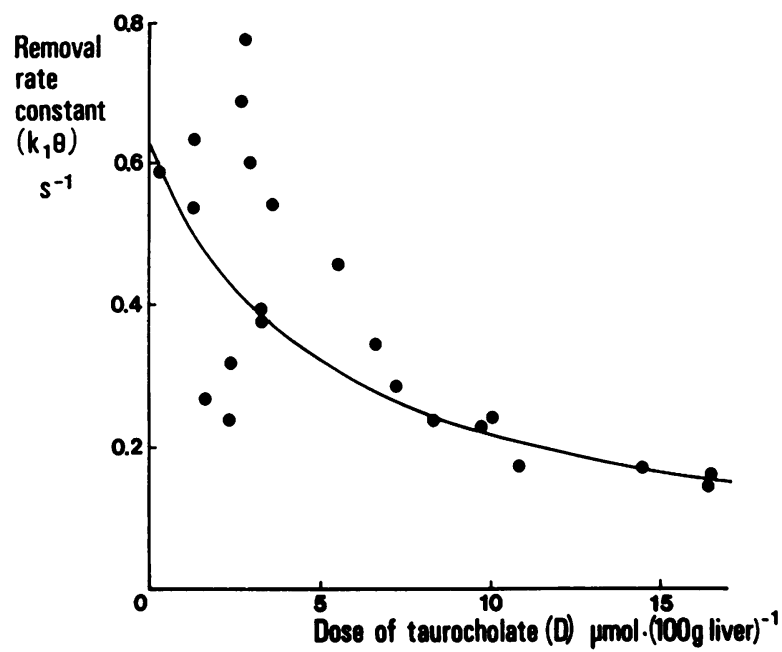

Figure 5 Influence of the dose of taurocholate on the removal rate constant, $k_{1} \theta$. The fraction of the dose extrated per second decreased with increasing doses of taurocholate.

transformed into :

$$
\frac{D}{k_{1} \theta D}=\frac{K_{D}+D}{V \max }
$$

The plot of $1 / k_{1} \theta$ against $D$ is shown in Fig. 8: a linear relationship was obtained with a correlation coefficient of $0.872(P<0.001)$; (c) after linear transformation of the data according to Lineweaver-Burk, when Eq. 3 has

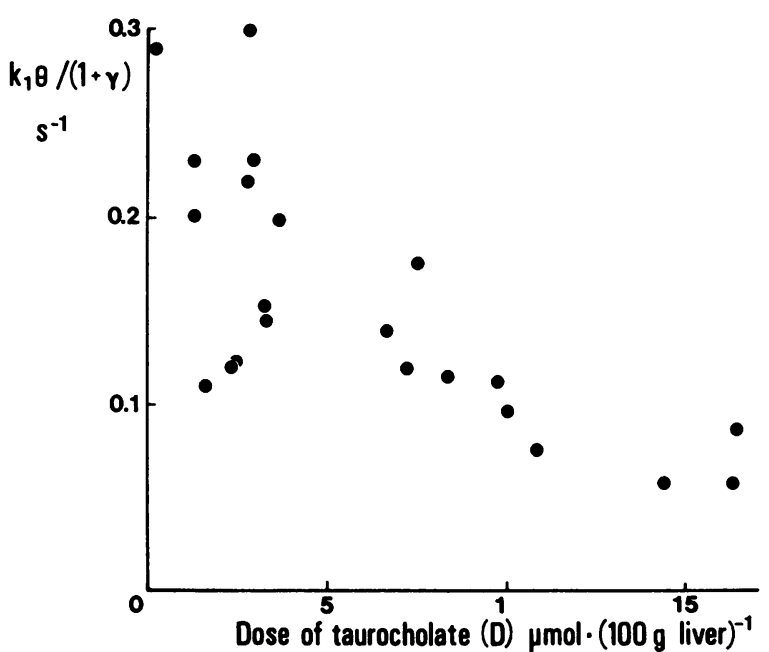

Figure 6 Influence of the dose of taurocholate on the factor $k_{1} \theta /(1+\gamma)$. This factor, expressed as $\mathrm{s}^{-1}$ (and representing milliliters of plasma transported per second per equivalent milliliters of total space, vascular + extracellular, outside the cells), decreased with increasing doses of taurocholate.

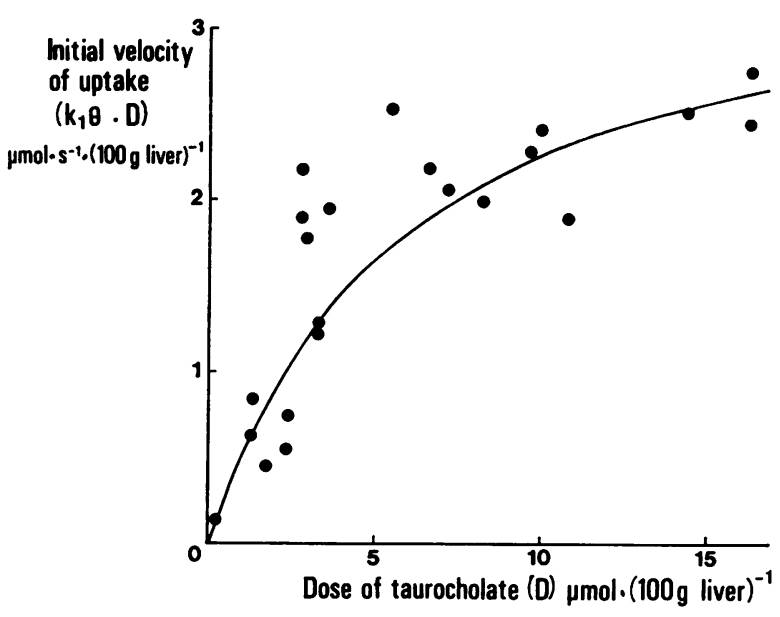

Figure 7 Influence of the dose of taurocholate on the initial velocity of uptake. The initial velocity of uptake increased nonlinearly with increasing doses of taurocholate. The rectangular hyperbola was identified in a computer.

been transformed into:

$$
\frac{1}{v}=\frac{1}{V \max }+\left(\frac{K_{D}}{V \max } \times \frac{1}{D}\right)
$$

The estimates of $V \max$ and $K_{D}$ obtained from the computer, from the Woolf linear transformation, and from the Lineweaver-Burk transformation are indicated on Table III.

\section{DISCUSSION}

Validity of the model. As shown previously by other authors (1), taurocholate is efficiently extracted by the liver. Our results clearly show that increasing the dose of taurocholate resulted in a decrease of the extracted fraction, suggesting a saturation phenomenon. Reichen

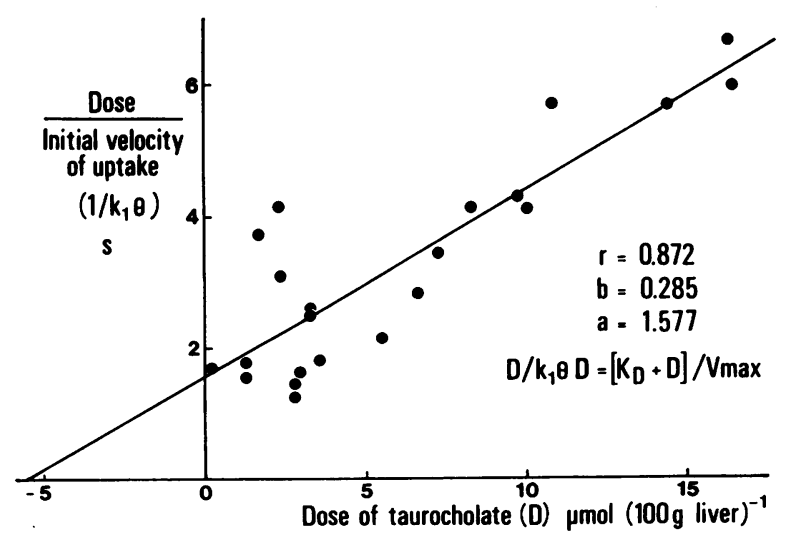

Figure 8 Woolf linear transformation. The data are the same as in Fig. 6. There is a linear relationship between $D / k_{1} \theta \times D$ (i.e. $1 / k_{1} \theta$ ) and $D$. The correlation coefficient was highly significant $(P<0.001)$. 
and Paumgartner (9) have also recently demonstrated that the uptake of taurocholate by the perfused rat liver was a saturable process. Goresky's model was utilized to calculate a removal rate constant from plasma into hepatic cells. The outflow profiles were consistent with this model, and the observation that no tailing was apparent in the dilution curve of taurocholate suggests that there was no significant return of taurocholate from cells to the extracellular space (8).

Albumin was used as reference extravascular substance for taurocholate. In most of the experiments the initial space of distribution of taurocholate was greater than that of albumin. This does not invalidate or preclude the use of the model, since any diffusible reference substance may be used $(3,7)$.

The curves were not corrected for catheter distortion (10): it has been shown that the influence of catheter distortion on this type of analysis was minimal (11).

Distribution space of taurocholate. The space of distribution of taurocholate corresponded to a mean value of $1.22 \pm 0.12$ (SD) times the distribution space of albumin. O’Máille, Richards, and Short have previously estimated a space of distribution for taurocholate greater than plasma volume (12). In contrast, the space of distribution of BSP is the same as that of albumin (3). This difference can be explained on the basis of the higher affinity of BSP for plasma albumin. In fact, the dissociation constant of the albumin-cholic acid complex calculated by Rudman and Kendall was $6.5 \times 10^{-4}$ (13), a much higher value than $5.8 \times 10^{-8}$, the dissociation constant of the albumin-BSP complex obtained by Baker and Bradley (14). Albumin has an apparently smaller immediately accessible space than the total extravascular space $(7,15)$. Sodium and sucrose are also extracellular indicators and their space of distribution is about 1.6 times the space of distribution of albumin $(7,15)$. Neither the proportion of the injected taurocholate dissociated from plasma albumin in the sinusoids nor the proportion of bile acids bound to albumin at normal plasma concentrations are known; therefore, it is only possible to assume that the calculated space of distribution of taurocholate is the algebraic sum of the space of a fraction bound to albumin (and so limited to the albumin space of distribution) and of the space of an unassociated fraction that diffuses instantaneously in the whole extravascular space. On this basis, if we assume a distribution space equal to that of albumin if completely bound, and a distribution space of 1.66 times that of albumin if completely unassociated, it is possible to estimate that approximately $60 \%$ of taurocholate would normally be bound to plasma albumin in the sinusoids. The space of distribution of taurocholate did not change with increasing doses, suggesting that the ratio of bound to un-
TABLE III

Determination of $\mathrm{Vmax}$ and $\mathrm{K}_{\mathrm{D}}$

\begin{tabular}{|c|c|c|c|}
\hline & \multirow[b]{2}{*}{$\begin{array}{l}\text { Rectangular } \\
\text { hyperbola* }\end{array}$} & \multicolumn{2}{|c|}{$\begin{array}{c}\text { Linear } \\
\text { transformation }\end{array}$} \\
\hline & & Woolf & $\begin{array}{c}\text { Lineweaver- } \\
\text { Burk }\end{array}$ \\
\hline$V \max , \mu \mathrm{mol} \cdot \mathrm{s}^{-1} \cdot 100 \mathrm{~g}$ liver $^{-1}$ & $4.53 \pm 1.48$ & 3.50 & 3.48 \\
\hline$K_{D}, \mu m o l \cdot 100 \mathrm{~g}$ liver -1 & $7.11 \pm 3.18$ & 5.52 & 5.79 \\
\hline
\end{tabular}

* Values obtained from the mathematical identification in a digital computer of the parameters of the hyperbola $( \pm S D)$.

bound taurocholate did not change significantly in the range of doses injected.

Kinetic characteristics of the uptake process. It was apparent that the removal rate constant decreased (Fig. 5) and that the initial velocity of uptake increased (Fig. 7) both nonlinearly when the dose of taurocholate increased. This strongly suggests a saturation phenomenon, as discussed for BSP (3), and is one criterion used to support the hypothesis that the transport of a substance from the plasma into the liver cell is carrier-mediated. The uptake would then be expected to follow MichaelisMenten kinetics. Consistent with this view is the finding that, when the Woolf transformation was applied to the data, a highly significant linear correlation was found between $D / k_{1} \theta D$ (i.e. $1 / k_{1} \theta$ ) and $D$ (Fig. 8) ; it is to be noted that the two terms of the correlation, namely $1 / k_{1} \theta$ and $D$, are computed independently.

The parameters of the kinetics $V \max$ (the maximal initial velocity of uptake) and $K_{D}$ (the dose yielding half-maximal velocity) were computed by mathematical identification with a computer program and from the linear transformations of Woolf and Lineweaver-Burk: the values obtained agreed reasonably well (Table III). This calculated value of the maximal initial velocity of uptake is approximately six times the maximal rate of steady state taurocholate excretion into bile $(16,17)$; this finding indicates that uptake is probably not ratelimiting in the overall process of taurocholate excretion.

The maximal removal rate and the dose that correspond to half-maximal removal rate are only minimal estimates, since they are based upon the assumption that the injected material is dispersed along the whole length of the hepatic sinusoids at zero time, rather than limited to a concentration wave (3). Moreover, in view of the very high extraction efficiency for taurocholate, and the possibility that the concentration of taurocholate decreases from the portal region to the centrolobular region, the value of $k_{1}$ may be higher toward the central lobular zone than at the periphery of the lobule. Thus, it may be an oversimplification to refer to a single value of $k_{1} \theta$ for a given dose of taurocholate; however, with 
the methods currently available, this is probably the best estimate that can be obtained.

In addition to the carrier-mediated uptake, a passive diffusion of taurocholate into liver cells could theoretically be possible; however, in our experiments, the finding of a space of distribution of taurocholate that did not increase when the dose increased excludes an important contribution of diffusion. Finally, portal concentration of endogenous bile acids was not considered. To minimize their influence on our results, the dogs were fasted $24 \mathrm{~h}$ before the experiment on the assumption that most of the bile acid pool was stored in the gallbladder and thus excluded from the enterohepatic circulation during the experiments.

Theoretically, the carrier-mediated transport system for taurocholate could be located either in the sinusoidal membrane, or in the cytoplasm, as previously suggested for BSP through its binding to the $\mathrm{Y}$ and $\mathrm{Z}$ proteins (18), or both. At the moment, there is no evidence that $\mathrm{Y}$ and $\mathrm{Z}$ proteins may be involved in the hepatic uptake of taurocholate; in particular, taurocholate did not displace BSP from $Y$ and $Z$ fractions in vitro (except at very high doses) (18). Our experiments cannot tell if the intracellular binding proteins play a role in the uptake process, and it is not possible to determine with the present method whether there is a passive transfer through the membrane followed by binding to a cytoplasmic carrier or whether the uptake process is mediated by a carrier located in the sinusoidal plasma membrane.

In conclusion, these studies show the applicability to the study of taurocholate uptake of a three-compartment model system with flow-limited distribution. This model allows the calculation of the initial extravascular space accessible to taurocholate, of the maximal initial transport capacity, and of the plasma concentration yielding half-maximal initial velocity. The results were thus considered to be consistent with the existence of a carriermediated transport system.

\section{ACKNOWLEDGMENTS}

The authors wish to thank Dr. C. Goresky for his help in preparing this manuscript, M. J.-L. Steimer (from the GERBIOS) for his help in computing the kinetic parameters, and Prof. J.-P. Benhamou for advice and support.

This work was supported by a grant No. 73-71643 from the Délégation Générale à la Recherche Scientifique et Technique, and by a grant No. 74500804 from the Institut National de la Santé et de la Recherche Médicale.

\section{REFERENCES}

1. O'Máille, E. R. L., T. G. Richards, and A. H. Short 1967. The influence of conjugation of cholic acid on its uptake and secretion: hepatic extraction of taurocholate and cholate in the dog. J. Physiol. (Lond.). 189: 337350.

2. Pratt, E. B., F. D. Burdick, and J. H. Holmes. 1952. Measurement of liver blood flow in unanesthetized dog using the bromsulfalein dye method. Am. J. Physiol. 171: 471-478.

3. Goresky, C. A. 1964. Initial distribution and rate of uptake of sulfobromophthalein in the liver. Am. J. Physiol. 207 : 13-26.

4. Hamilton, W. F., J. W. Moore, J. M. Kinsman, and R. G. Spurling. 1932. Studies on the circulation. IV. Further analysis of the injection method, and of changes in hemodynamics under physiological and pathological conditions. Am. J. Physiol. 99: 534-551.

5. Meier, P., and K. L. Zierler. 1954. On the theory of the indicator-dilution method for the measurement of flow and volume. J. Appl. Physiol. 6: 731-744.

6. Zierler, K. L. 1962. Theoretical basis of indicator-dilution methods for measuring flow and volume. Circ. Res. 10: 393-407.

7. Goresky, C. A. 1963. A linear method for determining liver sinusoidal and extravascular volumes. $\mathrm{Am}$. J. Physiol. 204: 626-640.

8. Goresky, C. A., G. G. Bach, and B. E. Nadeau. 1973. On the uptake of materials by the intact liver. The transport and net removal of galactose. J. Clin. Invest. 52: 991-1009.

9. Reichen, J., and G. Paumgartner. 1975. Kinetics of taurocholate uptake by the perfused rat liver. Gastroenterology. In press.

10. Goresky, C. A., and M. Silverman. 1964. Effect of correction of catheter distortion on calculated liver sinusoidal volumes. Am. J. Physiol. 207: 883-892.

11. Goresky, C. A., G. G. Bach, and B. E. Nadeau. 1973. On the uptake of materials by the intact liver. The concentrative transport of rubidium-86. J. Clin. Invest. 52: 975-990.

12. O'Máille, E. R. L., T. G. Richards, and A. H. Short. 1969. Observations on the elimination rates of single injections of taurocholate and cholate in the dog. Quart. J. Exp. Physiol. 54 : 296-310.

13. Rudman, D., and F. E. Kendall. 1957. Bile acid content of human serum. II. The binding of cholanic acids by human plasma proteins. J. Clin. Invest. 36: 538-542.

14. Baker, K. J., and S. E. Bradley. 1966. Binding of sulfobromophthalein (BSP) sodium by plasma albumin. Its role in hepatic BSP extraction. J. Clin. Invest. 45: 281-287.

15. Bravo, I. R., and D. L. Yudilevich. 1971. Liver distribution and uptake of molecules studied by rapid indicator-dilution technique. Am. J. Physiol. 221: 14491455.

16. Wheeler, H. O., P. L. Mancusi-Ungaro, and R. T. Whitlock. 1960. Bile salt transport in the dog. J. Clin. Invest. 39 : 1039-1040. '(Abstr.)

17. O'Maille, E. R. L., T. G. Richards, and A. H. Short. 1965. Acute taurine depletion and maximal rates of hepatic conjugation and secretion of cholic acid in the dog. J. Physiol. (Lond.). 180: 67-79.

18. Levi, A. J., Z. Gatmaitan, and I. M. Arias. 1969. Two hepatic cytoplasmic protein fractions, $Y$ and $Z$, and their possible role in the hepatic uptake of bilirubin, sulfobromophthalein, and other anions. J. Clin. Invest. 48: 2156-2167. 